\title{
Study of pre induction transvaginal ultra-sonographic cervical length and its comparison with bishop score in predicting successful labor induction
}

\section{Santosh Khajotia, Madhuri Sharma*, Mool Chand Khichar, Manoj Gupta, Kavita Choudhary}

Department of Obstetrics and Gynecology, SPM College and Associated Group of Hospitals, Bikaner, Rajasthan, India

Received: 02 April 2021

Accepted: 03 May 2021

\section{*Correspondence:}

Dr. Madhuri Sharma,

E-mail: sharmamadhuri100@yahoo.in

Copyright: (C) the author(s), publisher and licensee Medip Academy. This is an open-access article distributed under the terms of the Creative Commons Attribution Non-Commercial License, which permits unrestricted non-commercial use, distribution, and reproduction in any medium, provided the original work is properly cited.

\begin{abstract}
Background: Induction of labor means initiation of uterine contraction, after period of viability by any method (medical, surgical or combined) before spontaneous onset of labor for the purpose of vaginal delivery. The condition of cervix or favorability is important for successful labor induction. Assessment of cervix has been used as a predictor of successful vaginal delivery. Induction of labor carried out in approximately $20 \%$ of all pregnancies. Aim and objectives of the current study were to compare the predictive value of trans-vaginal ultra-sonographic measurement of cervical length versus Bishop score prior to induction of labor in predicting the mode of delivery and maternal and fetal outcome.

Methods: This prospective observational study was conducted in the department of obstetrics and gynecology, Sardar Patel medical college and associated group of hospitals, Bikaner between February to November 2020. Study group included 100 pregnant women in which induction of labor was performed at 37-42 weeks of gestation.

Results: Bishop Score appears to be a better predictor than the cervical length with sensitivity of 1.00 and a specificity of 0.12 compared to 0.52 and 1.00 respectively. In the receiver operating characteristic curves, the cut-off point for the prediction of successful induction taken was $2.6 \mathrm{~cm}$ cervical length and $>4$ for the bishop score.

Conclusions: TVS cervical length could be used as alternative to Bishop score for prediction of successful labor induction in the sitting where the appropriate equipment and expertise are available. Bishop score and TVS cervical length both are good predictors of successful induction of labor.
\end{abstract}

Keywords: Cervical length, TVS, USG, Bishop score

\section{INTRODUCTION}

Induction of labor means initiation of uterine contraction, after period of viability by any method (medical, surgical or combined) before spontaneous onset of labor for the purpose of vaginal delivery. The condition of cervix or favorability is important for successful labor induction. Assessment of cervix has been used as a predictor of successful vaginal delivery. Induction of labor carried out in approximately $20 \%$ of all pregnancies. ${ }^{1}$ The commonest indication for induction is prolonged pregnancy. $^{2-4}$

The traditional method of predicting whether an induced labor will result in successful vaginal delivery is based on the pre-induction favorability of cervix as assessed by the Bishop score ${ }^{5}$. Bishop developed a standardized cervical scoring system called the Bishop score. Calder modified the original Bishop score in 1974 which is known as modified Bishop score. He replaced the effacement of 
cervix denoted as percentage in the original score with length of cervix in centimeters. However Bishop score assessment is subjective method and several studies demonstrated a poor predictive value for outcome of induction due to controversy in assessment by different examiners. 5

Recently, trans-vaginal ultra-sonography has increased the role in obstetrics in induction of labor. Trans-vaginal sonographic (TVS) measurement of cervical length has primarily focused on detecting cervical changes in women at risk for preterm delivery. ${ }^{6}$ Trans-vaginal ultrasonography allows visualization of cervix beyond a closed external OS and measures the cervical length accurately without much inter-observer variation, especially in cases of non-palpable cervix on digital examination. TVS measurement of cervix could represent a more accurate assessment of the cervix than digital examination, because of supravaginal portion of cervix usually comprised about $50 \%$ of cervical length, is very difficult to assess digitally in closed cervix. Transvaginal ultra-sonographic cervical length measurement is objective method.

The rate of labor progression related to certain identifiable pre-labor characteristics of cervix. The validity of scoring systems for predicting the course of induced labor has been reported in terms of time from start of induction until onset of labor and the mode of delivery. Pre-induction favorability of cervix is assessed by Bishop score. ${ }^{7}$

When the cervix becomes as thin as the adjacent lower uterine segment, it is completely or $100 \%$ effaced. Cervical dilatation is determined by estimating the average diameter of the cervical opening by sweeping the examining finger from the margin of the cervical opening on one side to that on the opposite side. The cervix is said to be dilated fully when diameter measures $10 \mathrm{~cm}$, because the presenting part of term size new born usually can pass through a cervix which is fully dilated.

\section{Transvaginal ultrasound measurement}

The first study of human cervix using trans-vaginal ultrasound was conducted in 1980s. Current recommendations for performance of TVS of cervix are as follows: the women examined in the dorsal lithotomy position, with empty urinary bladder and a trans-vaginal probe, covered by condom, is slowly inserted into vagina. The probe placed in the anterior fornix of vagina, obtaining a sagittal view of cervix, with long axis view of echogenic endocervical mucosa along the length of canal. Then probe is withdrawn until image is blurred and reapplied just enough pressure to restore the image (to avoid excessive pressure on cervix which can elongate it). The image is magnified so that the cervix occupies at least $2 / 3^{\text {rd }}$ of the image, external and internal os are well seen. Views obtained at least three measurements and the shortest best measurement in millimeters is recorded.
Although TVS of cervix is usually straight forward but there is some anatomical and technical difficulties encountered in about $1 / 4^{\text {th }}$ of patients. ${ }^{8}$

\section{Anatomical difficulties}

Anatomical difficulties faced are; focal myometrial contraction they may obscure the internal OS and make the cervix appear longer than it is and endocervical mucus or polyps- they may appear to separate the anterior and posterior borders of endocervical canal and make the cervical measurement shorter than it is.

\section{Technical difficulties}

Technical difficulties faced are; pressure distortion even minimal pressure on the cervix falsely elongates the cervical length measurement. Increased echogenicity within cervix or just posterior to it usually indicates excessive probe pressure. ${ }^{9}$

\section{Method of cervical ripening}

Chemical method; prostaglandins are the current method of choice used for induction of cervical ripening. Prostaglandin E2; it has greater collagenolytic properties and also sensitizes the myometrium to oxytocin. Intracervical application of Dinoprostone gel (PGE2) 0.5 $\mathrm{mg}$ is the gold standard for cervical ripening. ${ }^{10}$ Misoprostol (PGE1); it is used either transvaginally or orally for induction of labor. Oral use is less effective than vaginal administration. The dose is $25 \mathrm{mcg}$, vaginally every 4 hours. ${ }^{11}$ Mechanical method; It acts by release of endogenous prostaglandins from the membrane and maternal deciduas to induce labor or cervical ripening by trans cervical Foleys catheter or membrane stripping.

\section{Aim and objectives}

Aim and objectives of current study were; to compare the predictive value of trans-vaginal ultra-sonographic measurement of cervical length versus Bishop score prior to induction of labor in predicting the mode of delivery and maternal and fetal outcome.

\section{METHODS}

Current study prospective observational study was conducted in the department of obstetrics and gynecology, Sardar Patel medical college and associated group of hospitals, Bikaner between February to November 2020. Study group included 100 pregnant women in which induction of labor was performed at 3742 weeks of gestation.

\section{Inclusion criteria}

Inclusion criteria of current study were; age 20-35 years; indications like pre-eclampsia, prolonged pregnancy, 
mild intra uterine fetal growth restriction; singleton fetus; Bishop score $\leq 6$; cephalic presentation with live fetus and absence of uterine contractions; Intact membrane.

\section{Exclusion criteria}

Subjects not fitting in following criteria were excluded from study; fetal malpresentation; ante partumhemorrhage; previous uterine incision; contraindications for prostaglandins (allergy, bronchial asthma, hypotension ,palpitation); suspicion of fetal distress on admission; patient in active phase of labor; multiple gestation; presence of severe maternal and fetal compromise e.g. severe PIH, severe IUGR, heart disease etc. and ruptured membrane.

\section{Procedure}

Baseline characteristics and indication for induction were noted. Cervical length was measured by a trans-vaginal ultrasound scanner. All ultrasound measurement were carried out according to standard protocol i.e. women were examined in dorsal lithotomy position with an empty urinary bladder. Once the cervical canal was identified, the probe was withdrawn slightly so there was no pressure of tip of the probe on the cervix. A sagittal plane through the cervix was identified where the external cervical os, the cervical canal, and internal cervical os was visible. The length of cervix was measured from the outer to inner cervical os as a straight line. Cervical length measured $3 \mathrm{~cm}$ away from posterior fornix. It was important to include only that part of cervical canal that was bordered by the endocervical mucosa. Three measurements were obtained and the shortest, technically best measurement in the absence of uterine contractions was recorded. We performed digital examination of the cervix for consistency, effacement, dilatation, position and station of the presenting part as described in Bishop score and was noted on a proforma.

Induction of labor was carried out according to standard protocol. The agent used for induction of labor was dinoprostonegel $0.5 \mathrm{mg}$ within 1 hour of cervical assessment. Regular fetal monitoring was done during induction of labor by Doppler or stethoscope. The patient was reassessed after 6 hours. If she was not exhibit regular uterine contractions and cervical change, a second dose of dinoprostone gel was administrated intracervically. Maximum of 3 doses can be repeated. Subsequent dose was withheld if: the patient was in active labor; rupture of membrane; if cervical effacement $>60 \%$ and cervical dilatation $\geq 3 \mathrm{~cm}$; regular uterine contractions 2-3 in 10 minutes.

\section{RESULTS}

Distribution of cases showing relationship between the Bishop's score and the mode of delivery is shown in (Table 1). Majority of cases i.e. 66 (66\%) had Bishop score $>4$ and delivered vaginally after successful induction. Rest of cases i.e. 34 (34\%) had Bishop score $\leq 4$, Out of which 16 delivered vaginally and 18 cases underwent caesarean section.

Table 1: Bishop score.

\begin{tabular}{|c|c|c|c|c|}
\hline \multirow{2}{*}{ Parameters } & \multicolumn{4}{|l|}{ Score } \\
\hline & 0 & 1 & 2 & 3 \\
\hline $\begin{array}{l}\text { Cervical } \\
\text { dilatation }(\mathrm{cm})\end{array}$ & $<1$ & $1-2$ & $2-4$ & $>4$ \\
\hline $\begin{array}{l}\text { Effacement } \\
(\%)\end{array}$ & $0-30$ & $40-50$ & $60-70$ & $>80$ \\
\hline Consistency & Firm & Medium & Soft & - \\
\hline Position & Posterior & $\begin{array}{l}\text { Mid } \\
\text { position }\end{array}$ & Anterior & - \\
\hline Head station & -3 & -2 & $-1,0$ & $+1,+2$ \\
\hline
\end{tabular}

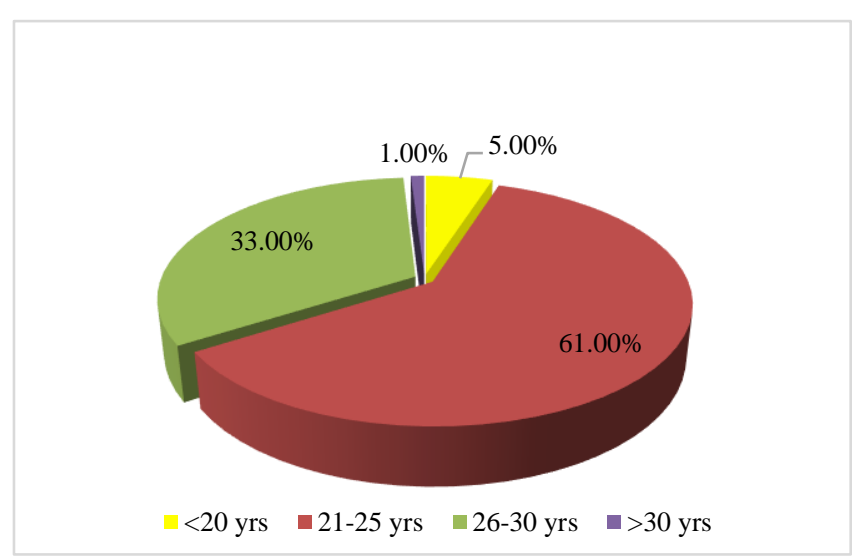

Figure1: Distribution of cases according to the maternal age group.

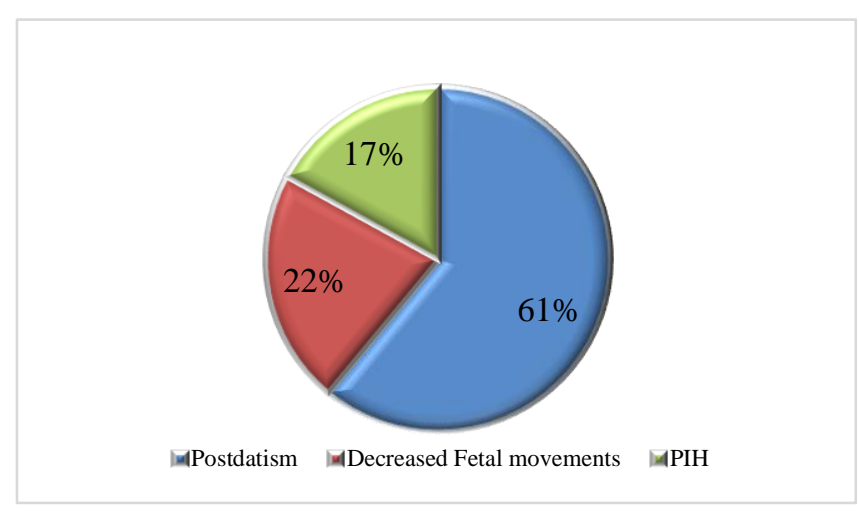

Figure 2: Distribution of cases according to the indication for induction.

Table 2: Distribution of cases showing relationship between the Bishop's score and the mode of delivery.

\begin{tabular}{|c|c|c|c|c|c|c|}
\hline \multirow{2}{*}{$\begin{array}{l}\text { Bishop } \\
\text { score }\end{array}$} & \multicolumn{2}{|c|}{$\begin{array}{l}\text { Vaginal } \\
\text { delivery }\end{array}$} & \multicolumn{2}{|c|}{ LSCS } & \multicolumn{2}{|c|}{ Total } \\
\hline & $\mathbf{N}$ & $\%$ & $\mathbf{N}$ & $\%$ & $\mathbf{N}$ & $\%$ \\
\hline$\leq 4$ & 16 & 16 & 18 & 18 & 34 & 34 \\
\hline$>4$ & 66 & 66 & 0 & 0 & 66 & 66 \\
\hline Total & 82 & 82 & 18 & 18 & 100 & 100 \\
\hline
\end{tabular}


Distribution of cases showing relationship between cervical length and the mode of delivery is shown in (Table 2). Majority of cases 79 (79\%) had cervical length of $\geq 2.5 \mathrm{~cm}$ measured by TVS. Out of 79 cases 61 delivered vaginally and 18 cases underwent caesarean section. Rest of 21 (21\%) cases had cervical length $<2.5$ $\mathrm{cm}$ and all were delivered vaginally after successful induction. Fetal outcome of current study is shown in (Table 3). The mean birth weight was $2.90 \pm 0.32 \mathrm{~kg}$ and the range of birth weight was between $2.3 \mathrm{~kg}$ to $3.8 \mathrm{~kg}$. Mean APGAR score at 1 minute was $8.80 \pm 1.17$ and the range of score was between 6 to 10, means minimum score at 1 minute was 6 and maximum was 10 . Mean APGAR score at $5 \mathrm{~min}$ was $9.85 \pm 0.59$ and the range of score was between 7 to 10 . Out of 100 neonates 6 were admitted to NICU.

Table 3: Distribution of cases showing relationship between cervical length and the mode of delivery.

\begin{tabular}{|lllllll|}
\hline \multirow{2}{*}{$\begin{array}{l}\text { TVS cervical } \\
\text { length (cms) }\end{array}$} & \multicolumn{2}{l}{$\begin{array}{l}\text { Vaginal } \\
\text { delivery }\end{array}$} & \multicolumn{2}{l}{ LSCS } & \multicolumn{2}{c|}{ Total } \\
& $\mathbf{N}$ & $\mathbf{\%}$ & $\mathbf{N}$ & $\mathbf{\%}$ & $\mathbf{N}$ & $\mathbf{\%}$ \\
\hline $\mathbf{2 . 5}$ & 21 & 21 & 0 & 0 & 21 & 21 \\
\hline $\mathbf{2 . 5}$ & 61 & 61 & 18 & 18 & 79 & 79 \\
\hline Total & 82 & 82 & 18 & 18 & 100 & 100 \\
\hline
\end{tabular}

Majority of cases $82(82 \%)$ delivered vaginally which had mean Bishop score $4.51 \pm 1.28$ and mean cervical length $2.63 \pm 0.48 \mathrm{~cm}$ (Table 4). Rest of the $18(18 \%)$ cases underwent caesarean section which had mean Bishop score $3.66 \pm 1.83$ and mean cervical length $3.36 \pm 0.46 \mathrm{~cm}$. Majority of cases $97(97 \%)$ had induction to delivery interval $<24$ hours which had mean Bishop score $4.74 \pm 1.56$ and mean cervical length $2.76 \pm 0.32 \mathrm{~cm}$. Out of 100,76 cases had induction to active phase interval <12 hours which had mean Bishop score $5.43 \pm 0.79$ and mean cervical length $2.68 \pm 0.25 \mathrm{~cm}$. Though Bishop score has high sensitivity than cervical length, specificity and positive predictive value of the trans vaginal cervical length is $100 \%$. Significant predictive value is obtained for Bishop score $=0.002$, $\mathrm{p}=0.07$. So, Bishop score $\geq 4$ was found to be better predictor of successful induction of labor in terms of delivery within 24 hours when compared to trans-vaginal cervical length. However, Bishop score appears to be a better predictor than the cervical length with sensitivity of 1.00 and a specificity of 0.12 compared to 0.52 and 1.00 respectively. In the receiver operating characteristic curves, the cut-off point for the prediction of successful induction taken was $2.6 \mathrm{~cm}$ cervical length and $>4$ for the bishop score.

Table 4: Fetal outcome.

\begin{tabular}{|lll|}
\hline Variable & Mean \pm SD & Range \\
\hline Birth weight & $2.90 \pm 0.32$ & $2.30-3.80$ \\
\hline APGAR at 1 minute & $8.80 \pm 1.17$ & $6-10$ \\
\hline APGAR at 5 minutes & $9.85 \pm 0.59$ & $7-10$ \\
\hline NICU admission & 6 & \\
\hline
\end{tabular}

Table 5: Correlation of the outcome measures with mean Bishop score and cervical length.

\begin{tabular}{|lllll|}
\hline $\begin{array}{l}\text { Outcome } \\
\text { measures }\end{array}$ & $\mathbf{N}$ & $\%$ & $\begin{array}{l}\text { Bishop } \\
\text { score }\end{array}$ & $\begin{array}{l}\text { Cervical } \\
\text { length }(\mathbf{c m})\end{array}$ \\
\hline $\begin{array}{l}\text { Induction to } \\
\text { active phase } \\
\text { interval <12 } \\
\text { hours }\end{array}$ & 76 & 76 & $5.43 \pm 0.79$ & $2.68 \pm 0.25$ \\
\hline $\begin{array}{l}\text { Induction to } \\
\text { delivery } \\
\text { interval <24 } \\
\text { hours }\end{array}$ & 97 & 97 & $4.74 \pm 1.56$ & $2.76 \pm 0.32$ \\
\hline $\begin{array}{l}\text { Total number } \\
\text { of vaginal } \\
\text { deliveries }\end{array}$ & 82 & 82 & $4.51 \pm 1.28$ & $2.63 \pm 0.48$ \\
\hline
\end{tabular}

Table 6: Comparison of Bishop score and cervical length measured by TVS.

\begin{tabular}{|llllll|}
\hline Variable & $\begin{array}{l}\text { Sensitivity } \\
(\boldsymbol{\%})\end{array}$ & $\begin{array}{l}\text { Specificity } \\
(\%)\end{array}$ & $\begin{array}{l}\text { PPV } \\
(\boldsymbol{\%})\end{array}$ & $\begin{array}{l}\text { NPV } \\
(\boldsymbol{\%})\end{array}$ & P value \\
\hline Bishop score $\geq \mathbf{4}$ & 100 & 12 & 77.32 & 100 & 0.002 \\
\hline TVS Cervical length $\leq \mathbf{2 . 6}$ & 52.58 & 100 & 100 & 6.12 & 0.07 \\
\hline
\end{tabular}

\section{DISCUSSION}

In the present study most common age group was 21-25 year, with mean age 24.5 years. This was comparable with the study done by Chandra et al where mean age was $27.9 \pm 5.2$ year. $^{12}$ Study done by Kaur et al also comparable to our study where most of cases were of age $\leq 30$ years with mean age being 26 years. ${ }^{13}$ In current study majority of cases i.e. $82 \%$ delivered vaginally which had mean Bishop score $4.51 \pm 1.28$ and rest of cases i.e. $18 \%$ underwent caesarean section which had mean Bishop score $3.66 \pm 1.83$. This was comparable with the study done by Ron et al where cases which underwent successful induction had mean Bishop score 5.9 and cases which underwent failed induction had mean Bishop score 3.8. ${ }^{14}$ Study done by Yanik et al also comparable to our study where cases delivered vaginally had mean

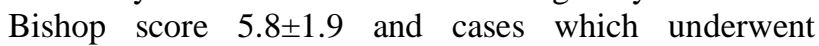
caesarean section had mean Bishop score 2.6 \pm 1.9 . $^{15}$ 
In current study majority of cases i.e. $82 \%$ delivered vaginally which had mean cervical length $2.6 \pm 0.48 \mathrm{~cm}$ and rest of cases i.e. $18 \%$ underwent caesarean section which had mean cervical length $3.3 \pm 0.49 \mathrm{~cm}$. This was comparable with the study done by Ron et al where cases which underwent successful induction had mean cervical length $28 \mathrm{~mm}$ and cases which underwent failed induction had mean cervical length $4 \mathrm{~mm} .{ }^{14}$ Study done by Yanik et al also comparable to our study where cases delivered vaginally had mean cervical length $2.6 \pm 0.99 \mathrm{~cm}$ and cases which underwent caesarean section had mean cervical length $3.4 \pm 0.81 \mathrm{~cm}^{15}$

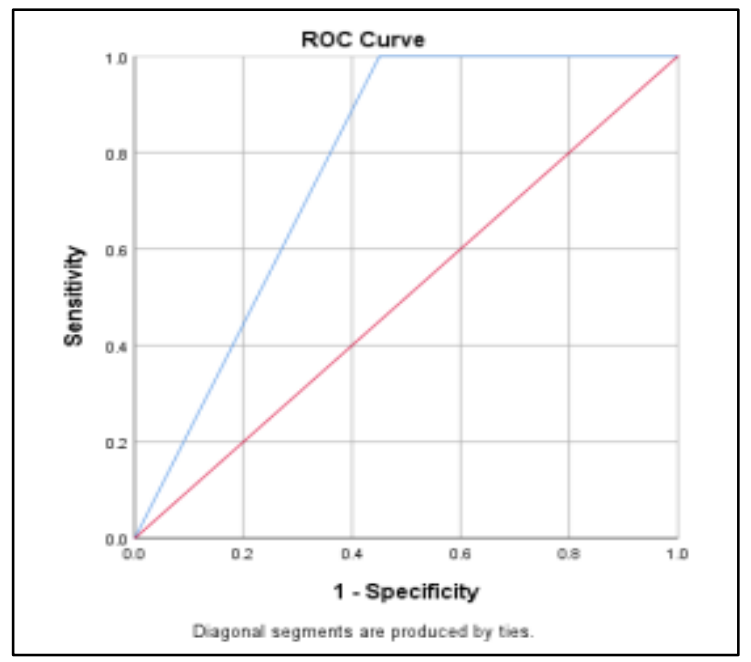

Figure 3: Receiver operating characteristic curves for the correlation of bishop score and Induction to delivery interval $<24$ hours, area under the curve is 0.775 .

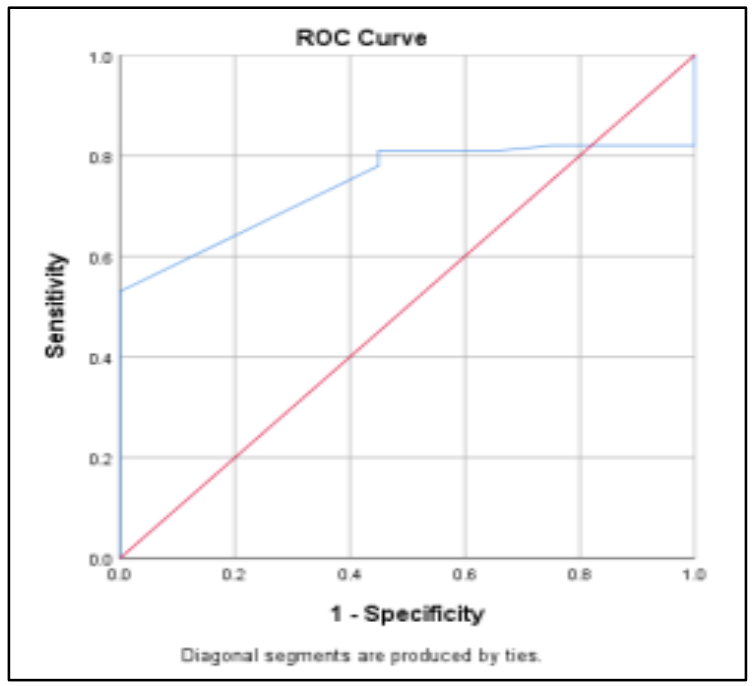

Figure 4: Receiver operating characteristic curves for the correlation of transvaginal cervical length and induction to delivery interval, area under the curve is $0.743(\mathbf{p}<0.05)$.

In current study, majority of cases i.e. 82 (82\%) had vaginal delivery and $18(18 \%)$ cases underwent caesarean section. This was comparable to the study done by Gabriel et al where out of 179 cases, 126 (70.39\%) delivered vaginally and $53(29.60 \%)$ cases underwent caesarean section. ${ }^{16}$ Study done by Tan et al also comparable to our study, where out of 249 cases 194 $(77.9 \%)$ delivered vaginally and $55(22.1 \%)$ cases underwent caesarean section. ${ }^{17}$

In current study out of 100 cases, 18 cases underwent caesarean section. Out of 18 cases, 16 cases for failed induction and 2 cases for nonprogress of labor underwent caesarean section. This was comparable with the study done by Brown et al where out of 50 cases, 7 cases underwent caesarean section. ${ }^{18}$ Out of 7 cases, 5 cases for failure to progress and 2 cases for prolonged labor underwent caesarean section.

In current study 76 cases had induction active phase interval $<12$ hours which had mean Bishop score $5.43 \pm 0.79$ and mean cervical length $2.68 \pm 0.25 \mathrm{~cm}$. Ninetyseven cases had induction delivery interval $<24$ hours which had mean Bishop score 4.74 \pm 1.56 and mean cervical length $2.76 \pm 0.32 \mathrm{~cm}$. This was comparable with the study done by Balaji et al where 55 cases had induction- active phase interval $<12$ hours which had mean Bishop score 4.6 \pm 0.7 and mean cervical length $2.4 \pm 0.3 \mathrm{~cm} .{ }^{19}$ Seventyfour cases had induction delivery interval $<24$ hours which had mean Bishop score $4.1 \pm 1$ and mean cervical length $2.5 \pm 0.4 \mathrm{~cm}$. In current study we plotted ROC curves to see the correlation between Bishop score and induction to delivery interval and TVS cervical length and induction to delivery interval. Area under the curve in case of Bishop score is 0.775, it is higher than the area under the curve in case of TVS cervical length i.e. 0.743. So Bishop score is better than TVS cervical length. In our study Bishop score $\geq 4$ had (sensitivity $100 \%$, specificity 12\%, PPV $77.32 \%$, NPV $100 \%$ and $\mathrm{p}=0.002$ ) and TVS cervical length $\leq 2.6 \mathrm{~cm}$ had (sensitivity $52.58 \%$, specificity $100 \%$, PPV $100 \%$, NPV $6.12 \%$ and $\mathrm{p}=0.07$ ). Bishop score has a significant $\mathrm{p}=0.002$ as compare to TVS cervical length $\mathrm{p}=0.07$ which is non-significant. So, Bishop score $\geq 4$ was found to be better predictor of successful induction of labor as compare to TVS cervical length. This was comparable with the study done by Khandelwal et al where they also plotted ROC curve. ${ }^{20}$ Area under the curve in case of Bishop score is 0.824 , it is higher than the area under the curve in case of TVS cervical length i.e. 0.625. So Bishop score is better than TVS cervical length. In their study Bishop score $\geq 4$ had (sensitivity $69 \%$, specificity $79 \%$, PPV 3.34, NPV 0.39 and $\mathrm{p}=0.0001$ ) and TVS cervical length $\leq 25 \mathrm{~mm}$ had (sensitivity $51 \%$, specificity $70 \%$, PPV 1.71, NPV 0.70 and $p=0.004$ ). They concluded Bishop score had highly significant $\mathrm{p}=0.0001$, so it is better than TVS cervical length as a predictor of successful induction of labor. Study done by Balaji et al contradictory to current study where Bishop score $\geq 4$ had (sensitivity $70.3 \%$, specificity $45.5 \%$, PPV $89.7 \%$, NPV $18.5 \%$ and $\mathrm{p}=0.296)$ and TVS cervical length $\leq 2.6 \mathrm{~cm}$ had (sensitivity $58.8 \%$, specificity $100 \%$, PPV $100 \%$, 
NPV 26.2\% and $\mathrm{p}=0.001)$. They concluded TVS cervical length had highly significant $\mathrm{p}=0.001$ so TVS cervical length $\leq 2.6 \mathrm{~cm}$ is a better predictor of successful induction of labor as compare to Bishop score.

\section{CONCLUSION}

Though further studies are mandatory to reach sound conclusions, available data suggests that both TVS cervical length evaluation before induction of labor and prediction of cervical inducibility obtained by the Bishop score are safe, well tolerated and useful. The result of current study shows that Bishop score is a better predictor of successful labor induction as compared to TVS cervical length. However, TVS cervical length could be used as alternative to Bishop score for prediction of successful labor induction in the sitting where the appropriate equipment and expertise are available. Bishop score and TVS cervical length both are good predictors of successful induction of labor.

Funding: No funding sources

Conflict of interest: None declared

Ethical approval: The study was approved by the Institutional Ethics Committee

\section{REFERENCES}

1. Induction of labor., in evidence based clinical guideline number 9. Available at: https://www.nice. org.uk/guidance/cg70/evidence/cg70-induction-oflabour-full-guideline2. Accessed on 20 January 2021.

2. Cole RA, Howie PW, Magnaughton MC. Elective induction of labor. A randomized prospective trial. Lancet. 1975;1:767-70.

3. Sue-A-Quan AK, Hannah M E, Cohen M, Foster G A. Effect of labor induction on rates of still birth and Caesarean Section in post term pregnancies. Can Med Assoc J. 1999;160(8):1145-9.

4. Sande HA, Tuveng J, Fontelien TA. Prospective randomized study of induction of labor. Int J Gynecol Obstet. 1983;21:333-6

5. Rageth JC, Kernen B, Saurenmann E, Unger C. Premature contractions: possible influence of sonographic measurement of cervical length on clinical management. Ultrasound Obstet Gynecol. 1997;9(3):183-7.

6. Andersen HF, Nugent CE, Wanty SD, Hayashi RH. Prediction of risk of preterm delivery by ultrasonographic measurement of cervical length. Am J Obstet Gynecol. 1990;163(3):859-67.

7. Anderson HF. Transvaginal and trasabdominal Ultrasonography of the uterine cervix during pregnancy. J Clin Ultrasound. 1991;19:77-83.
8. Burger M, Weber-Rossler T, Willmann M. Measurement of the pregnant cervix by transvaginal sonography: an inter observer study and new standards to improve the inter observer variability. Ultrasound Obstet Gynecol. 1997;9:188-93.

9. Keirse MJNC, Chalmers I. Methods for inducing labor. In: Chalmers I, Enkin M, Keirse MJNC, eds. United Kingdom: Oxford University Press; 1989: 1057-79.

10. Shaala S, Darwish E, Anwar M. Cervical prostaglandin injection a novel method of administration for ripening the cervix and induction of labour. Int J Gynecol Obstetr. 1989;30:221-3.

11. Lo J, Alexander J, McIntire D. Ruptured membranes at term: randomized, double blind trial of oral misoprostol for labour induction. Obstet Gynecol. 2003;101:685-9.

12. Gabriel R, Darnaud T, Chalot F, Gonzalez N, Leymarie F, Quereux C. Transvaginal sonography of the uterine cervix prior to labor induction. Ultrasound Obstet Gynecol. 2002;19(3):254-25.

13. Cunningham L, Bloom D, Hoffman CS. Induction and augmentation of labor. 25th ed. New York: MC Graw- Hill; 2001:503-15.

14. Ware V, Raynor D. Transvaginal ultrasonographic cervical measurement as a predictor of successful labor induction. Am J Obstet Gynecol. 2000;182: 1030- 2.

15. Tan PC, Vallikkannu N, Suguna S, Quek KF, Hassan J. Transvaginal sonographic measurement of cervical length vs. Bishop score in labor induction at term: tolerability and prediction of Caesarean delivery. Ultrasound Obstet Gynecol. 2007;29(5):568-73.

16. Rozenberg P, Chevret S, Chastang C, Ville Y. Comparison of digital and ultrasonographic examination of the cervix in predicting time interval from induction to delivery in women with a low Bishop score. BJOG. 2005;112(2):192-6.

17. Won YB, Han SW, Kim EH. Clinical factors and ultrasound parameters to predict successful vaginal delivery following labour induction. $\mathrm{J}$ Obstet Gynaecol. 2020;40(3):360-366.

18. Watson WJ, Stevens D, Welter S, Day D. Factors predicting successful labor induction. Obstst Gynecol. 1996;88:990-2.

19. Khandelwal R, Patel P, Pitre D, Sheth T, Maitra N. Comparison of Cervical Length Measured by Transvaginal Ultrasonography and Bishop Score in Predicting Response to Labor Induction. J Obstet Gynaecol India. 2018;68(1):51-57.

20. Raynelda F, Lukas E, Qadar S, Chalid MT. Comparison of Bishop score and cervical length measurement through transvaginal ultrasound as prediction against labor induction. Asian Pacific J Reproduct. 2018;7:280-4.

Cite this article as: Khajotia S, Sharma M, Khichar MC, Gupta M, Choudhary K. Study of pre induction transvaginal ultra-sonographic cervical length and its comparison with bishop score in predicting successful labor induction. Int J Reprod Contracept Obstet Gynecol 2021;10:2335-40. 